\title{
The potential therapeutic efficacy of intravenous versus subconjunctival mesenchymal stem cells on experimentally ultraviolet-induced corneal injury in adult male albino rats
}

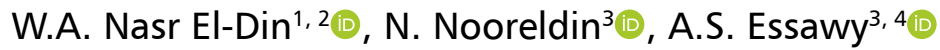 \\ ${ }^{1}$ Department of Anatomy, College of Medicine and Medical Sciences, Arabian Gulf University, Manama, Bahrain \\ 2Department of Human Anatomy and Embryology, Faculty of Medicine, Suez Canal University, Ismailia, Egypt \\ ${ }^{3}$ Department of Human Anatomy and Embryology, Faculty of Medicine, Menoufia University, Menoufia, Egypt \\ ${ }^{4}$ Anatomy Department, Ibn Sina National College for Medical Studies, Jeddah, KSA
}

[Received: 2 June 2021; Accepted: 23 August 2021; Early publication date: 10 September 2021]

Background: The $X$-rays and the visible light are the main source of ultraviolet radiation (UVR). About $90 \%$ of ultraviolet $B(U V B)$ is absorbed by the cornea which may promote corneal inflammation, oedema and damage of its epithelial layer. Bone marrow mesenchymal stem cells (BM-MSCS) have been demonstrated to ameliorate the injured corneal tissue and accelerate its wound healing. This study aimed to compare the healing effect of intravenous (IV) versus subconjunctival (SC) BM-MSCs on the rats' corneas subjected to UVB-irradiation.

Materials and methods: Ten rats were used as donors for BM-MSCs and the other 40 were allocated into four equal groups: group I (control group), group II (ultraviolet-irradiated group), group III (ultraviolet-irradiated + IV BM-MSCs-treated group) and group IV (ultraviolet-irradiated +SC BM-MSCs-treated group). Rats of all groups were euthanized after 3 weeks and the corneal specimens were processed for histopathological, immunohistochemical and electron microscopy assessment. Results: Ultraviolet-irradiated group showed remarkable thinning of epithelial thickness, wide partial epithelial separation, and desquamation. Neovascularisation of the disorganised stroma and disrupted Descemet's membrane were observed. The superficial and basal epithelial cells appeared irregular and separated by wide intercellular spaces and inflammatory cells. Immunohistochemical examination showed a significant decrease in proliferating cell nuclear antigen immunoreaction. In contrast, minimal changes were observed in rats treated with BM-MSCS with more improvement associated with the subconjunctival administration compared to IV route.

Conclusions: Local SC injection of BM-MSCs has an amazing regenerative efficacy on the corneal injury compared to the systemic IV route. (Folia Morphol 2022; 81, 4: 900-916)

Key words: ultraviolet radiation, corneal injury, mesenchymal stem cells, rats

Address for correspondence: Dr. W.A. Nasr El-Din, Department of Anatomy, College of Medicine and Medical Sciences, Arabian Gulf University, 26671, Manama, Bahrain and Department of Human Anatomy and Embryology, Faculty of Medicine, Suez Canal University, Ismailia, Egypt, tel: +97335173368, e-mail: waelamin2010@yahoo.com; waela@agu.edu.bh

This article is available in open access under Creative Common Attribution-Non-Commercial-No Derivatives 4.0 International (CC BY-NC-ND 4.0) license, allowing to download articles and share them with others as long as they credit the authors and the publisher, but without permission to change them in any way or use them commercially. 


\section{INTRODUCTION}

Annually, more than 1.5 million recent patients are presented with corneal blindness [28]. Because of the high cost and lack of the donors, corneal transplantations used as the treatment of only less than $5 \%$ of cases [18]. Scarring of the cornea and thinning of its stroma are the expected fate of corneal injuries, which may result in visual impairment [40].

Ultraviolet radiation (UVR) is a type of the electromagnetic radiation that found in $\mathrm{X}$-rays and visible light. Generally, UVR is divided into ultraviolet $A$ (UVA) accounts for $90 \%$ to $95 \%$ with a wavelength 320 $-400 \mathrm{~nm}$, and ultraviolet B (UVB) accounts for $5 \%$ to $10 \%$ with a wavelength $290-320 \mathrm{~nm}$. UVB is likely more harmful than UVA as it possesses an extra energy and more capacity to destroy tissue [14, 24].

Cornea and anterior segment of the eye absorb most of UVB radiation, so the inner eye segments are preserved from the damage of radiation. Nearly $90 \%$ of UVB radiation is absorbed by the cornea which has greater sensitivity to UVB injury [33]. Exposure to toxic dose of UVB radiation may induce corneal epithelial injury, oedema, photophthalmia and photokeratitis $[3,15]$. Corneal epithelial injury is composed of diminished viability of cells with degeneration of mitochondria and nuclei with a large number of apoptotic cells [63]. The cellular mechanism of injury may be due to antioxidant/prooxidant imbalance leading to oxidative stress [10]. Inadequately cleaved reactive oxygen species may lead to enhanced secretion of the proteolytic enzymes with significant activation of proinflammatory cytokines, causing creation of exaggerated inflammation, neovascularisation and apoptosis of the cornea in addition to alterations in the optics of the cornea [8]. Furthermore, injury of the endothelium of the cornea is the consequence of exposition to toxic doses of UVB resulting in blurring of vision [9]. Many causes are related photokeratitis such as welder's arc burns, snow blindness, lamps of metal halide, sunlamps and laboratory or germicidal ultraviolet lamps [17].

Mesenchymal stem cells (MSCs) are pluripotent undifferentiated cells that can proliferate and differentiate into various mature cells adipocytes, osteocytes and chondrocytes [57]. MSCs induce cellular differentiation leading to promotion of wound healing [51]. Furthermore, MSCs has an attractive powerful ability for self-renewal as well as restricted immunogenicity $[46,58]$, which encourage many researchers to study of the efficacy of MSCs to mini- mise inflammation and reconstruct the transparency of the cornea after its damage $[16,44,61]$. Bone marrow mesenchymal stem cells (BM-MSCs) greatly ameliorate the injured corneal surface and accelerate its wound healing after alkali burn [42, 62].

The aim of this study was to compare the potential healing efficacy of two methods of injection of intravenous (IV) versus subconjunctival (SC) BM-MSCs on UVB-irradiated corneas in adult male albino rats.

\section{MATERIALS AND METHODS}

Animals

All experimental procedures and animal maintenance were conducted in accordance with the roles and the guidelines of the Research Ethics Committee, Menoufia University, Faculty of Medicine with the ethical approval number (ANAT-8/2020-1). A total of 50 Sprague-Dawley male albino rats were utilised during this study (aged 3-4 weeks and weighing 230-260 g). They were purchased from the animal house of Faculty of Medicine, Ain Shams University, Cairo, Egypt and housed in the laboratory animal house unit of Kasr Al-Ainy, Faculty of Medicine, Cairo University, Cairo, Egypt. Two weeks before the experiment the rats were left for acclimation, kept in a monitored climate and exposed to a 12-hour light/dark cycle, with free access to food and tap water. Ten of the rats were used as donors for BM-MSCs and the other 40 were used for the experimental procedures.

\section{Experimental design}

The animals were allocated into four equal groups ( $n=10$ per group):

- Group I (control group): which was equally divided into; subgroup $A$ : the rats received IV injection of $0.1 \mathrm{~mL}$ phosphate-buffered saline (PBS); subgroup $B$ : the rats received $\mathrm{SC}$ injection of $0.1 \mathrm{~mL}$ PBS;

- Group II (ultraviolet-irradiated group): the left eyeballs of the rats were exposed to a narrow beam of UVR-B for 5 consecutive days;

- Group III (ultraviolet-irradiated + IV BM-MSCs-treated group): 1 week after the last session of ultraviolet exposure, the rats received IV injection of $0.1 \mathrm{~mL}$ PBS containing $1 \times 10^{6} \mathrm{MSC}$ in the lateral tail vein using a 25 -gauge needle slowly over 1 min [41];

- Group IV (ultraviolet-irradiated + SC BM-MSCs-treated group): the rats received local anaesthesia by anaesthetic eye drops and injection of 
$10 \%$ chloral hydrate $(4 \mathrm{~mL} / \mathrm{kg})$ then under an ophthalmic microscope, they received a single SC injection of $0.1 \mathrm{~mL}$ PBS containing $1 \times 10^{6} \mathrm{BM}-$ -MSCs 1 week after the last session of ultraviolet irradiation [19].

The rats of all groups were euthanized 26 days from the start of the experiment and half the eyeballs were enucleated then were submersed in $10 \%$ neutral buffered formalin solution and the other half were put in $2.5 \%$ glutaraldehyde for 24 hours. Thereafter the corneas were carefully dissected and processed for light microscopic and electron microscopic study.

\section{Induction of corneal injury by ultraviolet exposure}

The rats were anesthetised $10 \mathrm{~min}$ before the procedure by intraperitoneal injection of a mix of $2 \%$ Xylazine (10 mg/kg/body weight) and $10 \%$ Ketamine ( $60 \mathrm{mg} / \mathrm{kg} / \mathrm{body}$ weight). LS-1 tungsten halogen lamp with a spectral range 290-400 nm (supplying a $6.5 \mathrm{~W}$ output power) was provided as a pump for the source for a narrow beam of UVR-B which applied to the left cornea for $15 \mathrm{~min}$ per session [22].

\section{Isolation of BM-MSCs}

The donors' rats were sacrificed by cervical dislocation and their femoral and tibial bones were harvested under sterilised condition. BM-MSCs were isolated based on the following protocols [55]. In brief, the marrow cavity was flushed with PBS (Lonza, Belgium) in a 1-mL syringe with an 18-gauge needle. After collection of the cells by centrifugation at $400 \times \mathrm{g}$ for $10 \mathrm{~min}$, the BM-MSCs were resuspended at a density of 107 cells $/ \mathrm{mL}$ in $\alpha$-MEM Hank's medium. The cell pellet was suspended and plated into $25 \mathrm{~cm}^{2}$ culture plates (3 mL/plate) (Sigma-Aldrich, St. Louis, MO, USA). Isolated BM-MSCs were cultured with adding $10 \%$ foetal bovine serum (FBS), $0.5 \%$ penicillin/streptomycin and incubated at $37^{\circ} \mathrm{C}$ and $5 \% \mathrm{CO}_{2}$. The medium was changed on the day 3 and the non-adherent cells were discarded. The medium was changed every 48 hours.

\section{Passaging of BM-MSCs}

The primary cultured cells were kept in culture until reaching $80-90 \%$ confluence. Afterwards, the cells were trypsinised at $37^{\circ} \mathrm{C}$ by adding trypsin-EDTA (Gibco, South America) for $10 \mathrm{~min}$. Thereafter, the action of trypsin-EDTA was stopped by addition of $5 \mathrm{~mL}$ of complete medium (CM). Furthermore, each cell pellet suspension was centrifugated and resuspended in fresh
$\mathrm{CM}$ then distributed into 2-3 Petri dishes after counting the number of cells by the haemocytometer. Subculture of BM-MSCs repeated till reaching the $3^{\text {rd }}$ passage.

\section{Viability testing}

Trypan blue exclusion assay was performed to test the cell survival in the culture before transplantation. The viable cells appeared with transparent clear cytoplasm while the dead cells had blue cytoplasm. The viability was estimated to be greater $95 \%$ through the different passages was excellent [56].

\section{Stem cell characterisation and differentiation in vitro}

Mesenchymal stem cells were demonstrated and examined by the inverted microscope (Leica, Wetzlar, Germany) which revealed their characteristic shape (fusiform/spindle-shaped fibroblast-like cells), adherence capacity and the ability for multipotent differentiation into osteocytes, adipocytes and chondrocytes. Differentiation to osteocytes was recognised by using osteocytes StemPro ${ }^{\circledR}$ osteogenesis differentiation kit (Gibco, Grand Island, NY, USA) and stained with Alizarin Red S stain (Sigma-Aldrich). The adipocytes differentiation was recognized by using adipocytes StemPro ${ }^{\circledast}$ adipogenesis differentiation kit (Gibco, Grand Island, NY, USA) and stained with Oil Red O stain (Sigma-Aldrich, St. Louis, MO, USA). The chondrocytes differentiation was recognised by using chondrocytes StemPro ${ }^{\circledR}$ chondrogenesis differentiation kit (Gibco, Grand Island, NY, USA) and stained with Alcian Blue stain (Sigma-Aldrich) [7].

\section{Flow cytometric analysis}

For studying the phenotypic characters of BM-MSCs, the cells of the $3^{\text {rd }}$ passage were detached by adding $0.25 \%$ trypsin. Thereafter, PBS was applied for washing of cells. MSC markers CD 90 and CD 105 and the haematopoietic stem cell marker CD 45 were detected in the surface the cultured cells. This was carried out by using Fluorescence-Activated Cell Sorting (FACS) (BD Biosciences, Franklin Lanes, NJ, USA) in which the cells were incubated at $4^{\circ} \mathrm{C}$ in the dark for 20 min with $2 \mu \mathrm{L}$ fluorescein isothiocyanate (FITC)-conjugated rat monoclonal antibody against mouse CD 90 and CD 105 (BD Biosciences) and $5 \mu \mathrm{L}$ phycoerythrin (PE)-conjugated rat monoclonal antibody against mouse CD 45 (BD Biosciences). The samples were centrifuged at room temperature for 
5 min at $300 \times \mathrm{g}$, resuspended in $500 \mu \mathrm{L}$ PBS then analysed by the flow cytometry [7].

\section{Immunofluorescence cell labelling}

According to the manufacturer's protocol, BM-MSCs at the $2^{\text {nd }}$ passage were labelled with the red fluorescent dye PKH26 (Sigma-Aldrich). In summary, serum-free medium was utilised to wash BM-MSCs then the cells were resuspended in $1 \mathrm{~mL}$ of dilution buffer. An equal mixture volume of BM-MSCs suspension and the labelling solution containing $1 \times 10^{6}$ PKH26 were incubated at room temperature for $5 \mathrm{~min}$. The activity of the mixture was blocked by addition of $2 \mathrm{~mL}$ FBS and, finally, Dulbecco's modified Eagle's medium (DMEM)/F12 cells was applied 3 times for multiple cells washing. Then the cells were injected intravenously into rat tail vein. The corneas were examined with a fluorescence microscopy to detect and trace the transplanted cells stained with PKH26 [38].

\section{Histopathological study}

The corneas were immersed in 10\% neutral formalin (Sigma-Aldrich St. Louis, MO, USA) and processed for paraffin sections. $5 \mu \mathrm{m}$ thick sections were prepared and stained with haematoxylin and eosin (H\&E) stains, other sections were stained with Periodic Acid Schiff (PAS) stain for examination of the Descemet's membrane [4]. All sections were examined under an Olympus DP70 light microscope (Olympus, Tokyo, Japan).

\section{Immunohistochemistry}

Paraffin sections were deparaffinised in xylene and hydrated. Sections were incubated with primary antibodies after stopping the reaction of peroxidase by adding $10 \%$ hydrogen peroxide. Proliferating cell nuclear antigen (PCNA) antibody is a mouse monoclonal antibody at 1:400 dilution (Sigma-Aldrich, St. Louis, Missouri, USA). Antigen retrieval was applied for $30 \mathrm{~min}$ by steam heating the slides in a $1-\mathrm{mmol} / \mathrm{L}$ solution of EDTA (pH 8.0). After stopping of endogenous biotin reaction, staining was carried out by an automated immunostainer then by applying a streptavidin-biotin detection system (Dako, Glostrup, Denmark). Sections were counterstained with haematoxylin. Primary antibody (as a negative control) was changed by PBS [29].

\section{Transmission electron microscopy (TEM)}

Small corneal specimens were immersed for 2 hours in $2.5 \%$ buffered glutaraldehyde in $0.1 \mathrm{PBS}$ at $\mathrm{pH} 7.4$ and $4^{\circ} \mathrm{C}$, then replaced by $1 \%$ osmium tetroxide in
$0.1 \mathrm{~mol} / \mathrm{L}$ for 1 hour at $4^{\circ} \mathrm{C}$ to fix the specimens. After that, specimens were dehydrated in ascending serial dilution of ethanol $(50,70,90,95$ and 4 times $100 \%$, each for $30 \mathrm{~min}$ ) then dehydrated by acetone for 30 min. Finally, the fixed specimens were embedded in epoxy resin (Epoxy Embedding Medium Kit; Sigma). Semi- and ultra-thin sections were cut on ultramicrotome (RMC PT-XL PowerTome Ultramicrotome). Semithin $(1 \mu \mathrm{m})$ thick sections were prepared and stained with $1 \%$ toluidine blue and examined by using an Olympus BX61 light microscope. Ultrathin sections (70-90 nm) were cut by ultramicrotome then stained with $2 \%$ uranyl acetate as a principal stain and lead citrate as counter stain to be examined by using JEM-1400 Plus (JEOL, Japan) transmission electron microscope at the Electron Microscope Unit, Faculty of Science, Alexandria University, Alexandria, Egypt [30].

\section{Morphometric analysis}

All morphometric measurements were performed at a magnification of $\times 400$ by the Image ${ }^{\circledast}(1.50 \mathrm{e}$, USA) software using at least 5 sections per animal, and from each section 5 non overlapping fields were examined at Anatomy Department, Faculty of Medicine, Menoufia University by (Olympus BX40, Ships to USA). All measurements were carried out by the same investigator to avoid inter-observer errors.

The H\&E-stained sections were used to measure and estimate the corneal epithelial thickness then the results were recorded. The PAS-stained sections were utilized to investigate and measure the thickness of the Descemet's membrane and the colour intensity of PAS positive reaction then the means were calculated and reported.

Furthermore, the mean area per cent of PCNA was measured in the immune-stained sections in all studied groups.

\section{Statistical analysis}

The analysis of data was conducted with Statistical Package for the Social Science (SPSS) 18.0. One-way Analysis of Variance (ANOVA) followed by Tukey's post-hoc test was performed to compare among the studied groups. P-values $<0.05$ were regarded as a statistically significant.

\section{RESULTS}

\section{Morphology of isolated BM-MSCs}

On day 0 post-seeding, the cultured cells appeared rounded with different size while some of 

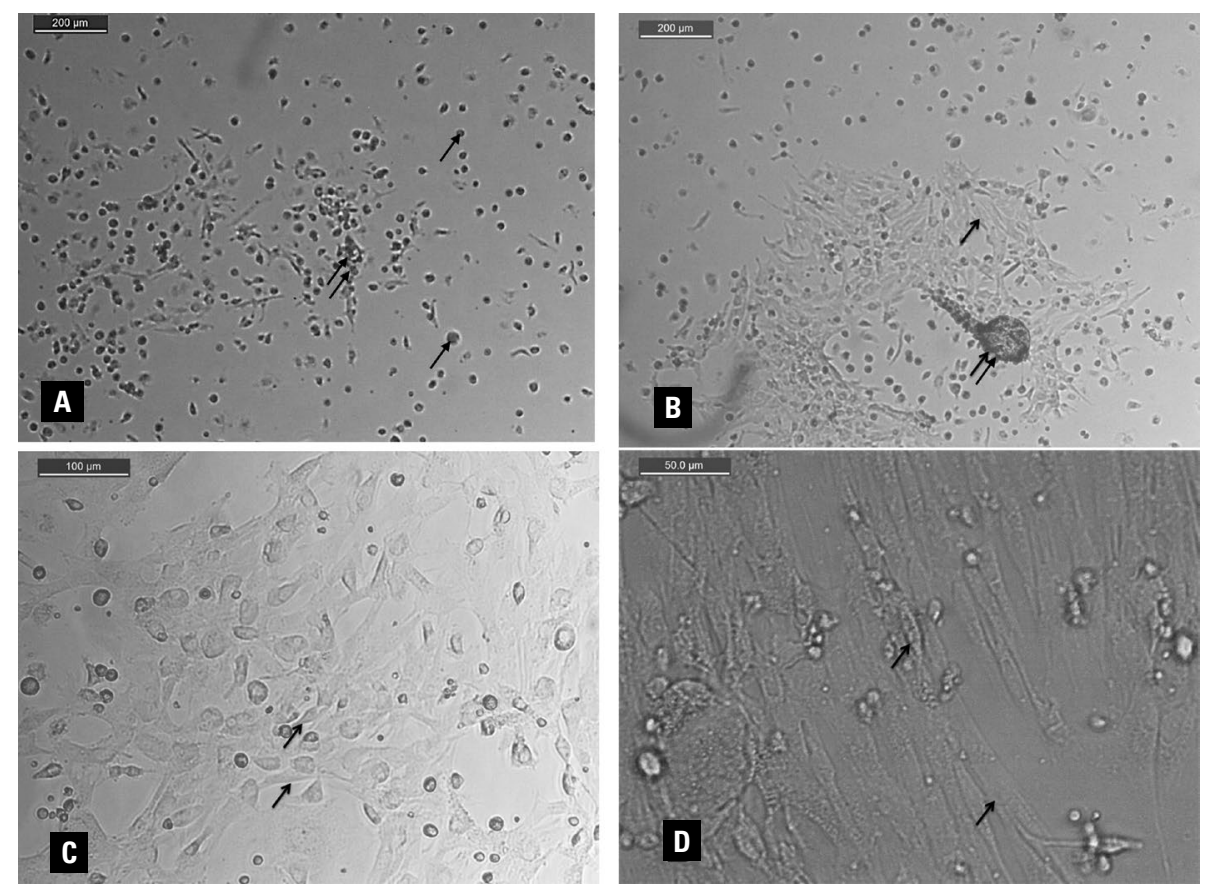

Figure 1. Mesenchymal stem cells (MSCs) are characterised in culture; A. On day 0 of MSCs isolation: cultured cells appear rounded with different size (arrow) while some of them are aggregated into small groups and floated (double arrow) $(40 \times$ ); B. On day 7, MSCs are long, spindle-shaped (arrow) with colony forming units (double arrows) $(40 \times)$; C. On day 10 , the number of cells are greatly increased and they acquire fusiform shape (arrow) $(100 \times)$; D. On day 14, the cell population appear confluent fibroblast like cells (arrow) $(200 \times)$.
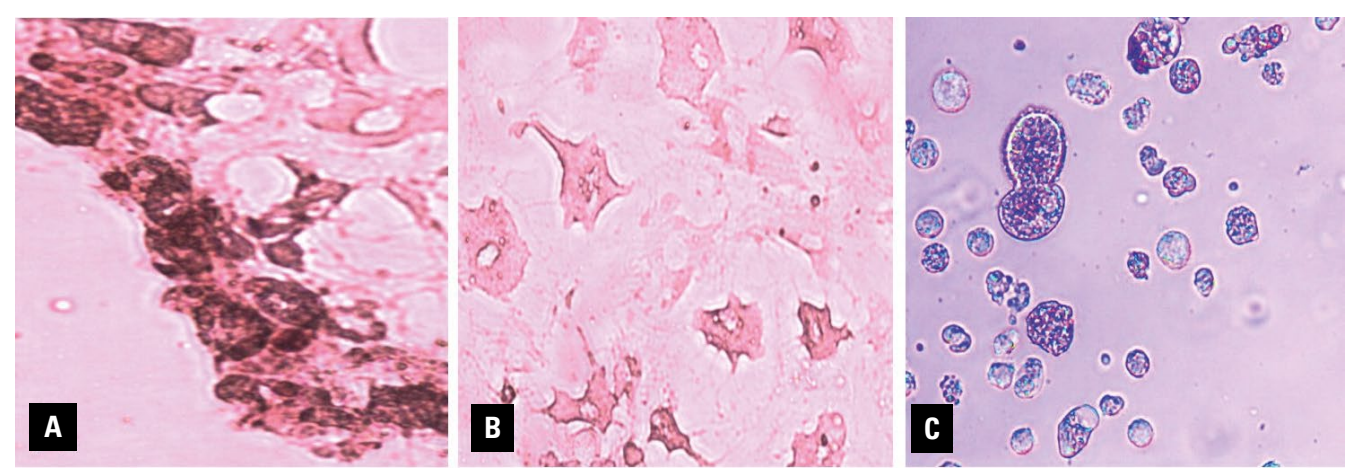

Figure 2. A. Mesenchymal stem cells (MSCs) are differentiated in culture into osteocytes and stained with Alizarin Red S stain; B. MSCs are differentiated in culture into adipocytes and stained with Oil Red $\mathbf{O}$ stain; C. MSCs are differentiated in culture into chondrocytes and stained with Alcian Blue stain.

them were aggregated into small groups and floated (Fig. 1A). One week after plating, MSCs were long, spindle-shaped and colony-forming units (Fig. 1B). On day 10 , the number of cells was greatly increased and they acquired fusiform shape (Fig. 1C). Fourteen days after plating, the cell population appeared fibroblast-like, and became confluent (Fig. 1D).

\section{Stem cell characterisation and differentiation in vitro}

Mesenchymal stem cells were differentiated to osteocytes stained with Alizarin Red S stain (Fig. 2A), differentiated to adipocytes stained with Oil Red $\mathrm{O}$ stain (Fig. 2B) and to chondrocytes stained with Alcian Blue stain (Fig. 2C).

\section{Phenotypic analysis of isolated BM-MSCs}

The surface markers of the isolated cells of the $3^{\text {rd }}$ passage were analysed by flow cytometry. Most of the cells expressed the MSC markers CD 90 (99.9\%) and CD 105 (90.38\%) while very few cells expressed the haematopoietic stem cell marker CD 45 (0.04\%) (Fig. 3). This proved that the isolated MSCs were purified BM-MSCs. 


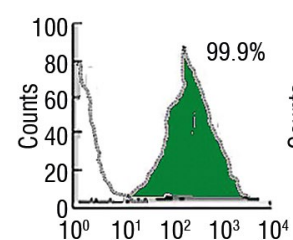

CD $90 \mathrm{PE}$

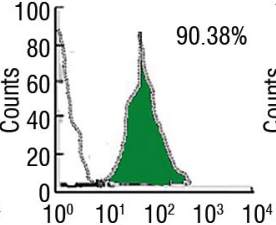

CD 105 PE

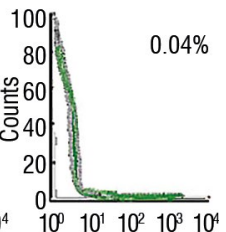

CD 45 FITC
Figure 3. A chart of the flow cytometric analysis of the surface antigens of mesenchymal stem cells: they are positive for CD 90 (99.9\%), CD 105 (90.38\%) and negative for CD 45 (0.04\%); FITC fluorescein isothiocyanate; PE — phycoerythrin.

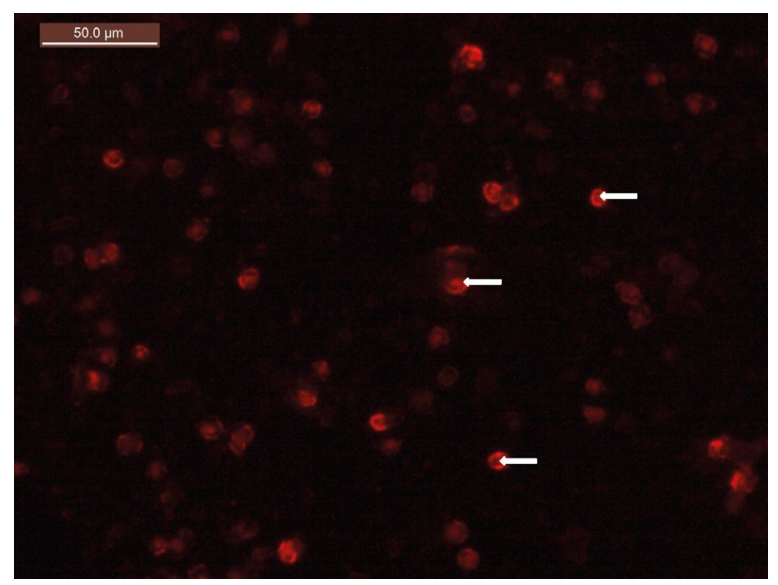

Figure 4. Immunofluorescence micrograph of the cornea of intravenous bone marrow mesenchymal stem cells-treated group showing the presence of numerous PKH26 labelled cells in the corneal tissue (arrows). Scale bar $=50 \mu \mathrm{m}$.

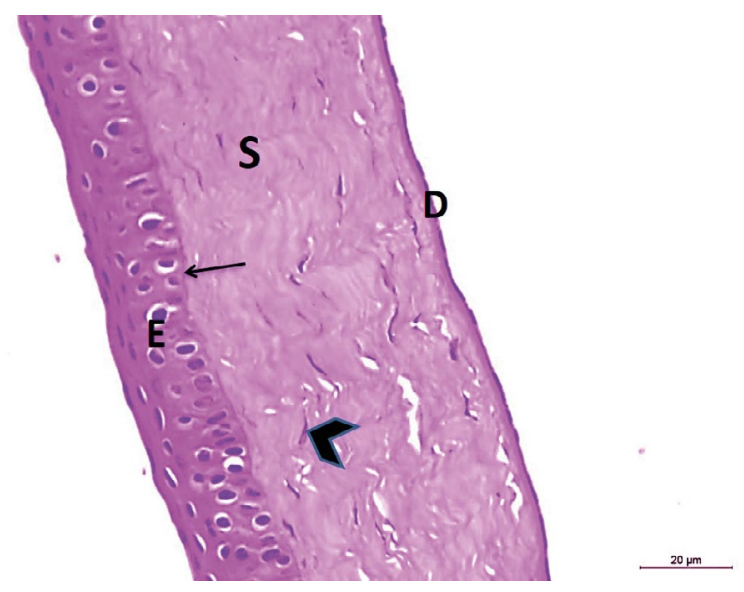

Figure 5. A photomicrograph of a section of the cornea of the control group showing normal corneal tissue consists of a nonkeratinised stratified squamous epithelium (E) which organized into multiple layers overlying Bowman's membrane (arrow). The stroma (S) constitutes most of the thickness of the cornea and consists of avascular well-organized collagen bundles with scattered spindle-shaped keratocytes (arrowhead). Descemet's membrane and single squamous Descemet's endothelial layer (D) are seen below the stroma. Haematoxylin and eosin $\times 400$; scale bar $=20 \mu \mathrm{m}$.

\section{Immunofluorescence cell labelling}

By using Carl Zeiss LSM 710 Duo Confocal microscope, PKH26-labelled cells were traced after 1 week of their IV injection of the group III. Many labelled cells were seen scattered in the corneal tissue (Fig. 4).

\section{Histopathological findings}

Regarding H\&E stain, the control subgroups showed a normal structure of the cornea. The stratified squamous non-keratinised epithelium was organized into 5 to 7 cell layers resting on a uniform basement Bowman's membrane. Bowman's membrane was a thin acidophilic membrane which separated the corneal epithelium from the underlying corneal stroma. The layer of corneal stroma forming the main bulk of corneal thickness and consisted of avascular regularly well-organized bundles of parallel collagen fibres with scattered spindle-shaped fibroblast (keratocytes). Descemet's membrane appeared as a homogenous and acidophilic thin layer below the stroma and was covered by a single layer of simple squamous Descemet's endothelium (Fig. 5). On the other hand, the ultraviolet-irradiated group showed remarkable histological alterations. The epithelium was mostly affected by wide partial separation and desquamation from the underlying stroma. Some epithelial cells showed pale vacuolated cytoplasm and deeply stained nucleus (Fig. 6A-C). Moreover, remarkable thinning of the corneal epithelial thickness was observed in this group compared to the control one. The collagen bundles of the stroma appeared thin and extensively disorganized with wide spaces among their fibres (Fig. 6B, C). Furthermore, neovascularisation and mononuclear cellular infiltration were also observed in the stroma (Fig. 6B). Descemet's membrane and its endothelial cells covering appeared highly disorganized and widely separated from the overlying stroma (Fig. 6C). Whereas, in the IV BM-MSCs-treated group, revealed moderate improvement of the corneal tissue in the form of restoration of organization and most of the thickness of the corneal epithelium. Vacuolated cytoplasm is still observed in some of the epithelial cells. Collagen bundles in the stroma are separated by many wide spaces. The Descemet's membrane and endothelium restored most of their normal features (Fig. 7A). The SC BM-MSCs-treated group showed marked improvement and restoration of many of the normal corneal tissue characteristics. The corneal epithelium was nearly similar to that of the control 


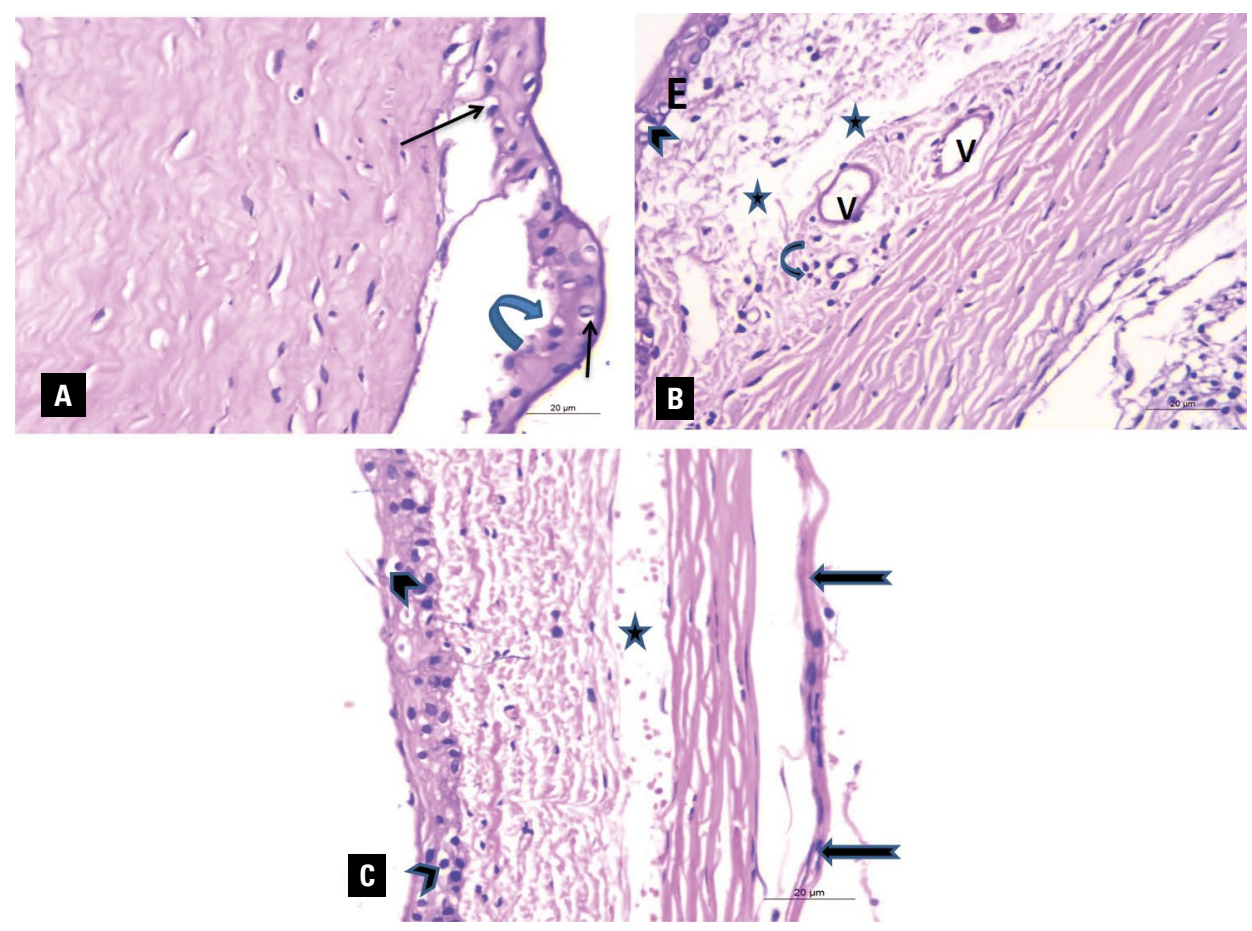

Figure 6. Photomicrographs of sections of the cornea of the ultraviolet-irradiated group; A. Wide partial separation and desquamation of most of the epithelial layer of the cornea from the underlying stroma (curved arrow). Some epithelial cells showing vacuolated cytoplasm (arrows); B. Thinning of the corneal epithelial thickness (E). Some epithelial cells showing vacuolated cytoplasm (arrowhead). The collagen bundles of the stroma appear thin and extensively disorganized with wide spaces between its fibres (asterisks). Neovascularisation (V) and mononuclear cellular infiltration (curved arrow) are also observed in the stroma; C. Many epithelial cells are distorted with deeply stained nuclei and vacuolated cytoplasm (arrow heads). The stroma showing thin dispersed irregular collagen fibres with wide spaces (asterisks). The Descemet's membrane and its covering endothelial cells appearing highly disorganized and widely separated from the overlying stroma (arrows). Haematoxylin and eosin $\times 400$; scale bar $=20 \mu \mathrm{m}$.
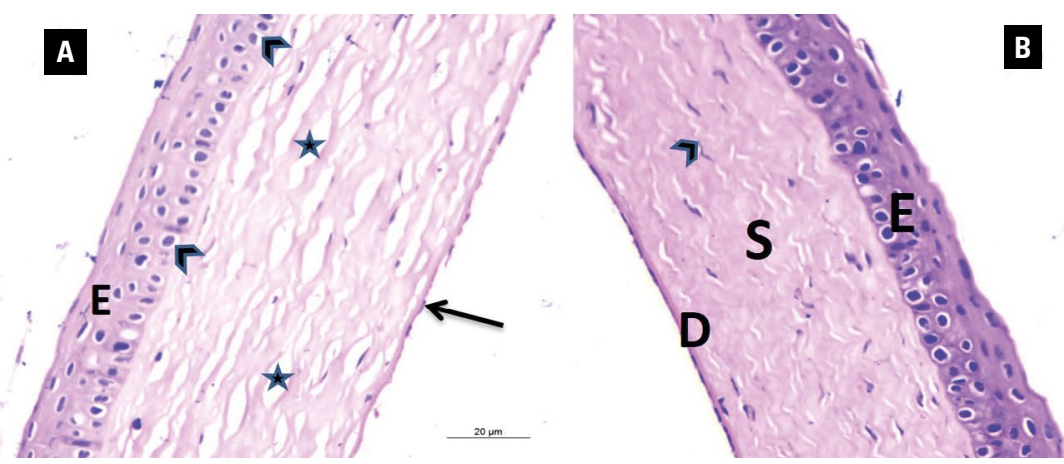

Figure 7. Photomicrographs of sections of the cornea of intravenous bone marrow mesenchymal stem cells (BM-MSCs)-treated group showing restoration of organization and most of the thickness of the corneal epithelium (E) (A).Vacuolated cytoplasm is still observed in some of the epithelial cells (arrow heads). Collagen bundles in the stroma are separated by many wide spaces (asterisks). The Descemet's membrane and endothelium restored most of their normal features (arrow). B. Subconjunctival BM-MSCs-treated group showing uniform organization and normal thickness of the corneal epithelium (E). The stroma showing regular organized collagen bundles (S) and spindle-shaped keratocytes (arrowhead). The Descemet's membrane appears acidophilic with intact covering Descemet's endothelium (D). Haematoxylin and eosin $\times 400$; scale bar $=20 \mu \mathrm{m}$.

group with uniform normal thickness, rested on intact basement membrane with absence of epithelial separation or desquamation from the underlying stroma. The stroma showed regular organized collagen bundles and spindle-shaped keratocytes. The Descemet's membrane appeared acidophilic with intact covering Descemet's endothelium (Fig. 7B).

Regarding PAS stain, the control subgroups showed a regular Descemet's membrane with a strong positive PAS reaction (Fig. 8A). On con- 


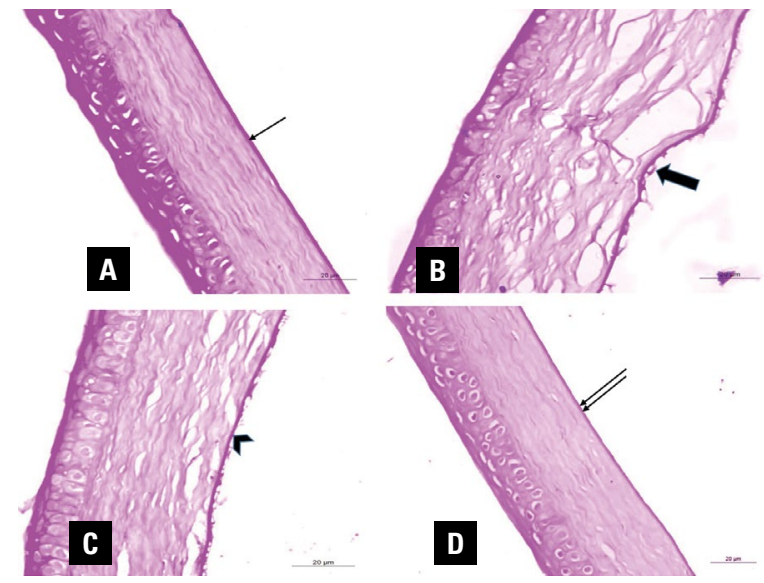

Figure 8. Photomicrographs of sections of the cornea of the studied groups; A. Control group showing a regular Descemet's membrane with a strong positive Periodic Acid Schiff (PAS) reaction (thin arrow); B. Ultraviolet-irradiated group showing a wavy, irregular Descemet's membrane with marked decrease in its thickness and weak PAS positive reaction (thick arrow); C. Intravenous bone marrow mesenchymal stem cells (BM-MSCs)-treated group showing a Descemet's membrane with a moderate positive PAS reaction (arrowhead); D. Subconjunctival BM-MSCs-treated group showing a regular thick Descemet's membrane with a strong PAS positive reaction (double arrow). PAS $\times 400$; scale bar $=20 \mu \mathrm{m}$.

trast, the ultraviolet-irradiated group exhibited a thin irregular and wavy Descemet's membrane with a weak PAS positive reaction (Fig. 8B). In IV BM-MSCs-treated group the Descemet's membrane showed partial restoration of normal appearance with a moderate positive PAS reaction (Fig. $8 \mathrm{C}$ ). The SC BM-MSCs-treated group demonstrated a regular thick Descemet's membrane with a strong PAS-positive reaction (Fig. 8D).

\section{Immunohistochemical results}

Proliferating cell nuclear antigen nuclear immunoexpression was applied to estimate corneal epithelial proliferation after MSCs injection. PCNA nuclear expression was mild in control group (Fig. 9A) and minimal in the ultraviolet-irradiated group (Fig. 9B). On the other hand, IV BM-MSCs-treated group exhibited a moderate PCNA nuclear expression (Fig. 9C) and SC BM-MSCs-treated group displayed a strong PCNA nuclear expression (Fig. 9D). PCNA was expressed in the basal epithelial layer in control and ultraviolet-irradiated groups, on contrast; the expression extended to the central and peripheral layers of the regenerated corneal epithelium in both IV BM-MSCs- and SC BM-MSCs-treated groups.

\section{Electron microscopic findings}

Ultrathin sections of the cornea of the control subgroups exhibited squamous cells in the superficial layer of the epithelial cells. Their nuclei appeared flattened and euchromatic. Intact desmosomes connected the adjacent cells together (Fig. 10A). The cells of intermediate layer showed normal nuclei with regular outline, mitochondria and rough endoplasmic reticulum (RER) appeared normal. Junctional complex was intact (Fig. 10B). The basal layer consisted of tall columnar cells with regular euchromatic nuclei and mitochondria inside their cytoplasm. These basal cells were resting on an intact continuous basement membrane and connected to each other by many intact regular electron-dense desmosomes (Fig. 10C). The stroma showed the presence of a well-organized collagen fibres. Spindle-shaped keratocytes with a euchromatic nucleus and little cytoplasm were observed in-between the collagen fibrils (Fig. 10D). A thick homogenous noncellular Descemet's membrane was clearly demonstrated underneath the stroma and lined by endothelial cell layer. The endothelial cells possessed electron-dense flattened euchromatic nucleus and scanty cytoplasm with multiple small pinocytotic vesicles (Fig. 10E).

Ultraviolet-irradiated group showed that the nucleus of squamous cells in the superficial layer of the epithelial cells appeared irregular and swollen. The cells were separated by wide intercellular spaces. Multiple inflammatory cells were observed infiltrating the intercellular tissue (Fig. 11A). Cells of intermediate layer appeared with indented and irregular nucleus. Loss of junctional complex represented as wide intercellular spaces were clearly seen. Mitochondria showed complete lysis of their cristae. (Fig. 11B). The cells of the basal layer were disturbed, disorganized and irregular in shape. Some of these cells had an irregular nucleus while others possessed a shrunken heterochromatic pyknotic nucleus. The cells were separated by wide intercellular spaces and inflammatory cells. The basement membrane was seen irregular and interrupted (Fig. 11C). The stroma composed of irregular disturbed collagen fibrils. The keratocytes appeared irregular in shape with heterochromatic nucleus and vacuolated cytoplasm. The stroma displayed a very wide area devoid of collagen fibrils (Fig. 11D). The Descemet's membrane appeared nonhomogeneous and distorted. The endothelial cells had an irregular nucleus with many variable sized vacuolations in the cytoplasm. The endothelial cells showed partial separation from the Descemet's membrane (Fig. 11E). 


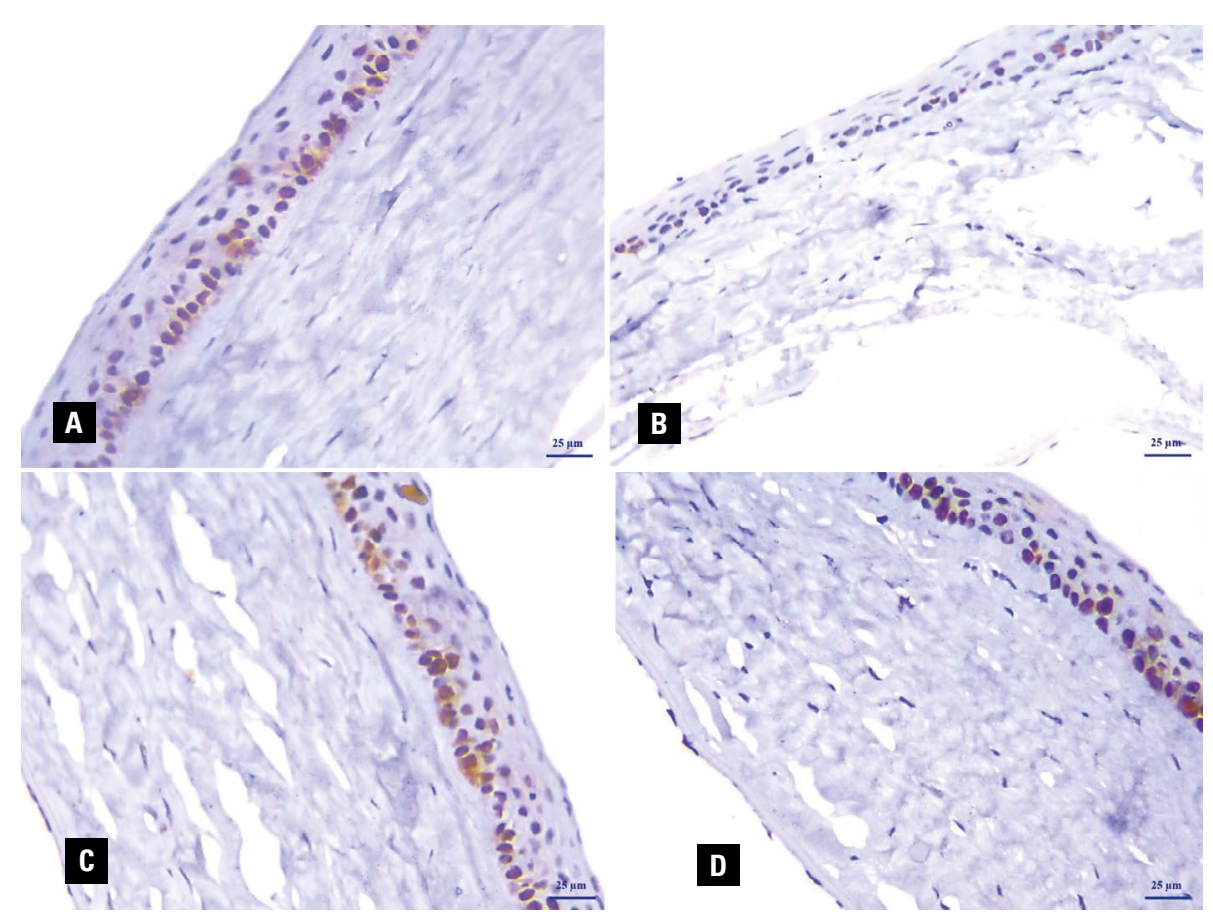

Figure 9. Photomicrographs of immunostaining sections of the cornea of the studied groups; A. Control group showing a mild nuclear immunoreactivity of the corneal epithelial cells; B. Ultraviolet-irradiated group exhibiting a minimal nuclear immunoreactivity of the corneal epithelial cells; C. Intravenous bone marrow mesenchymal stem cells (BM-MSCs)-treated group demonstrating a moderate nuclear immunoreactivity of the corneal epithelial cells; D. Subconjunctival BM-MSCs-treated group showing a strong nuclear immunoreactivity of the corneal epithelial cells. Proliferating cell nuclear antigen immunostaining; $\times 400$; scale bar $=25 \mu \mathrm{m}$.
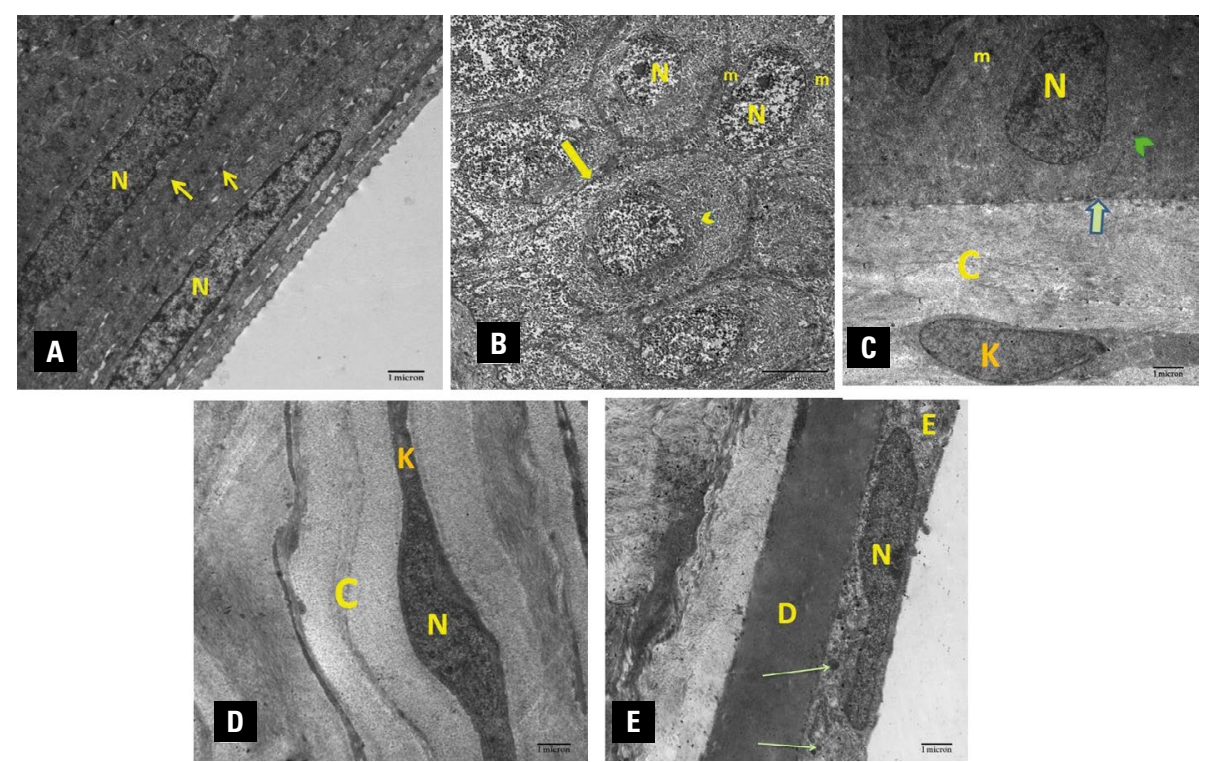

Figure 10. Electron micrographs of the cornea of the control group; A. Squamous cells are seen in the superficial layer of the epithelial cells. The nuclei of these cells appear flattened and euchromatic (N). Intact desmosomes connecting the adjacent cells together (arrows); B. Cells of intermediate layer of corneal epithelium. Nuclei appear normal with regular outline $(\mathrm{N})$; mitochondria $(\mathrm{m})$ and rough endoplasmic reticulum (arrowhead) are normal. Intact junctional complex (arrow); C. Columnar cells in the basal layer of the epithelial cells with euchromatic nuclei (N). The cells resting on an intact continuous basement membrane (arrow) and connected to each other by many intact regular electron-dense desmosomes (arrowhead). The mitochondria are seen inside its cytoplasm (m). Note: regular collagen bundles (C) surrounding a keratocyte $(\mathrm{K})$ in the stroma; D. The stroma showing the presence of an organized arrangement of the collagen fibres (C). A spindle-shaped keratocyte (K) with a euchromatic nucleus (N) and little cytoplasm; E. Thick homogenous noncellular Descemet's membrane (D) is lined by endothelial cell (E) with electron-dense flattened euchromatic nucleus $(\mathrm{N})$ and scanty cytoplasm containing multiple small pinocytotic vesicles (arrow). Transmission electron microscopy A, C, D, E: $\times 17500$; scale bar $=1 \mu \mathrm{m} ; \mathrm{B}: \times 8000$; scale bar $=4 \mu \mathrm{m}$. 


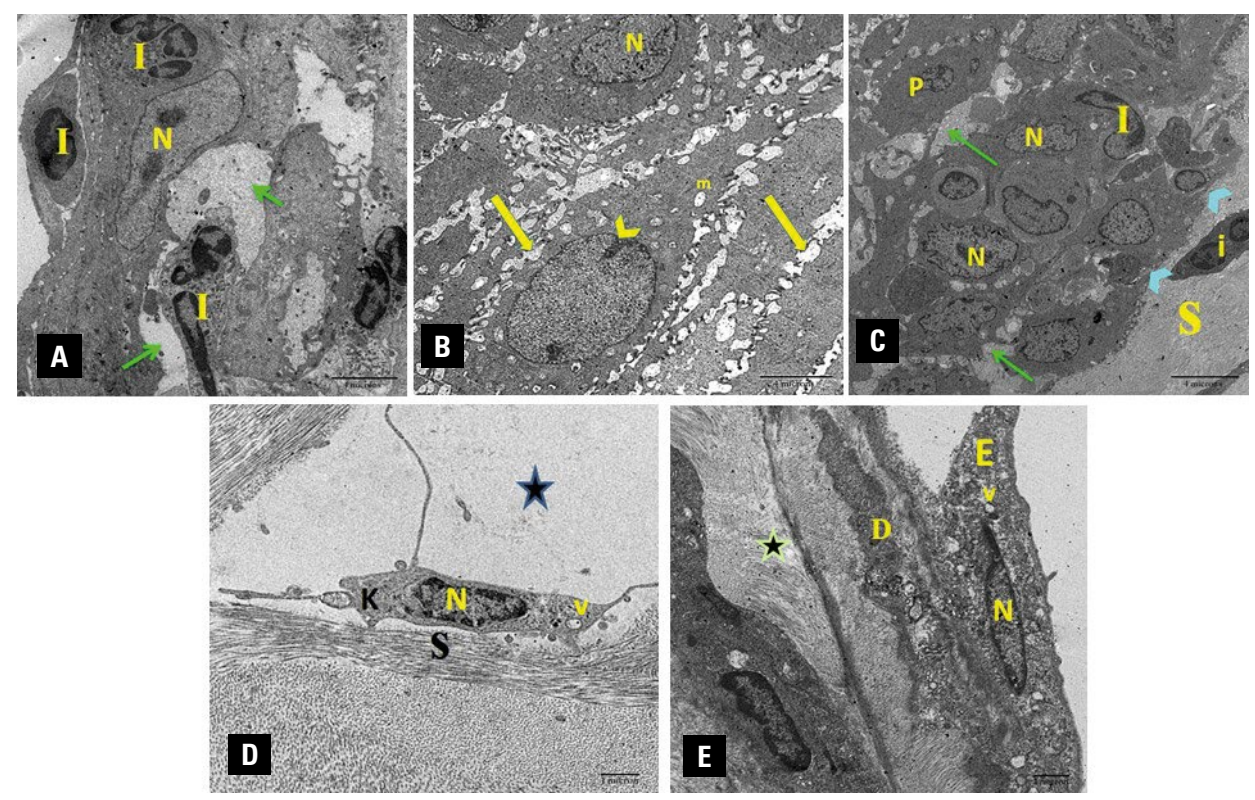

Figure 11. Electron micrographs of the cornea of the ultraviolet-irradiated group; A. Squamous cells of the superficial layer of the epithelial cells. The nucleus (N) appears irregular and swollen. The cells are separated by wide intercellular spaces (arrows). Multiple inflammatory cells (I) are observed infiltrating the intercellular tissue; B. Cells of intermediate layer with indented (arrowhead) and irregular nucleus (N), loss of junctional complex appears as wide intercellular spaces (arrows). Note, mitochondria $(\mathrm{m})$ can be observed with complete lysis of their cristae; C. Disturbed disorganized irregular shaped cells are noticed in the basal layer. Some of these cells have irregular nucleus (N) while others possess a shrunken heterochromatic pyknotic nucleus ( $p$ ). The cells are separated by wide intercellular spaces (arrows) and inflammatory cells (I). The basement membrane is seen irregular and interrupted (arrow heads). Note: An inflammatory cell (i) is observed in the region of stroma (S); D. The stroma (S) containing irregular disturbed collagen fibrils. A keratocyte (K) appears irregular in shape with heterochromatic nucleus (N) and vacuolated cytoplasm (v). The stroma exhibiting a very wide area devoid of collagen fibrils (asterisk); E. Descemet's membrane (D) appears nonhomogeneous and distorted. The endothelial cell (E) has an irregular nucleus (N) with many variable sized vacuolations in the cytoplasm (v). The endothelial cell shows partial separation from the Descemet's membrane. Note: The stroma showing distorted irregular collagen fibrils (asterisk). Transmission electron microscopy A-C: $\times 8000$; scale bar $=4 \mu \mathrm{m} ; \mathrm{D}, \mathrm{E}: \times 17500$; scale bar $=1 \mu \mathrm{m}$.

On the other hand, the IV BM-MSCs-treated group showed moderate improvement in all layers of the cornea. The squamous cells of superficial epithelial layer had an elongated euchromatic nucleus. Cells were connected together with intact continuous desmosomes; however, some cells were still separated by intercellular spaces (Fig. 12A). Cells of intermediate layer showed irregular nucleus. Mitochondria were observed with partial lysis of their cristae. Desmosomes appeared intact. There was a slight widening in the intercellular spaces (Fig. 12B). Some cells of the basal layer had an irregular euchromatic nuclei with multiple mitochondria while others had a pyknotic nucleus. The cells were resting on a slightly irregular basement membrane. Desmosomes appeared connecting the cells with each other (Fig. 12C). The stroma showed well-organized regular collagen fibrils. Some keratocytes were irregular in shape with distorted nuclei and surrounded by a large space devoid of collagen fibrils (Fig. 12D). The Descemet's membrane appeared thick, homogenous with a regular contour. The endothelial cells were distorted with many vacuolations in their cytoplasm (Fig. 12E).

The SC BM-MSCs-treated group revealed marked improvement and restoration of the normal features in all layers of the cornea. The squamous cells in the superficial epithelial layer had a flattened elongated euchromatic nucleus. The cells were attached together by desmosomes. Narrow intercellular spaces were still seen among the cells (Fig. 13A). Cells of intermediate showed nearly normal nuclei appear with regular outline. Mitochondria and RER were normal. The junctional complex showed focal areas of slightly widening in the intercellular space while the desmosomes were intact (Fig. 13B). The cells of basal layer possessed normal contour with an euchromatic mild indented nuclei with many mitochondria resting on a regular intact continuous basement membrane. Intact desmosomes connected the epithelial cells to each other (Fig. 13C). The stroma showed well-organized regular collagen fibrils. A spindle-shaped keratocytes with a euchromatic nucleus appeared in-between the collagen fibrils (Fig. 13D). The Descemet's membrane 


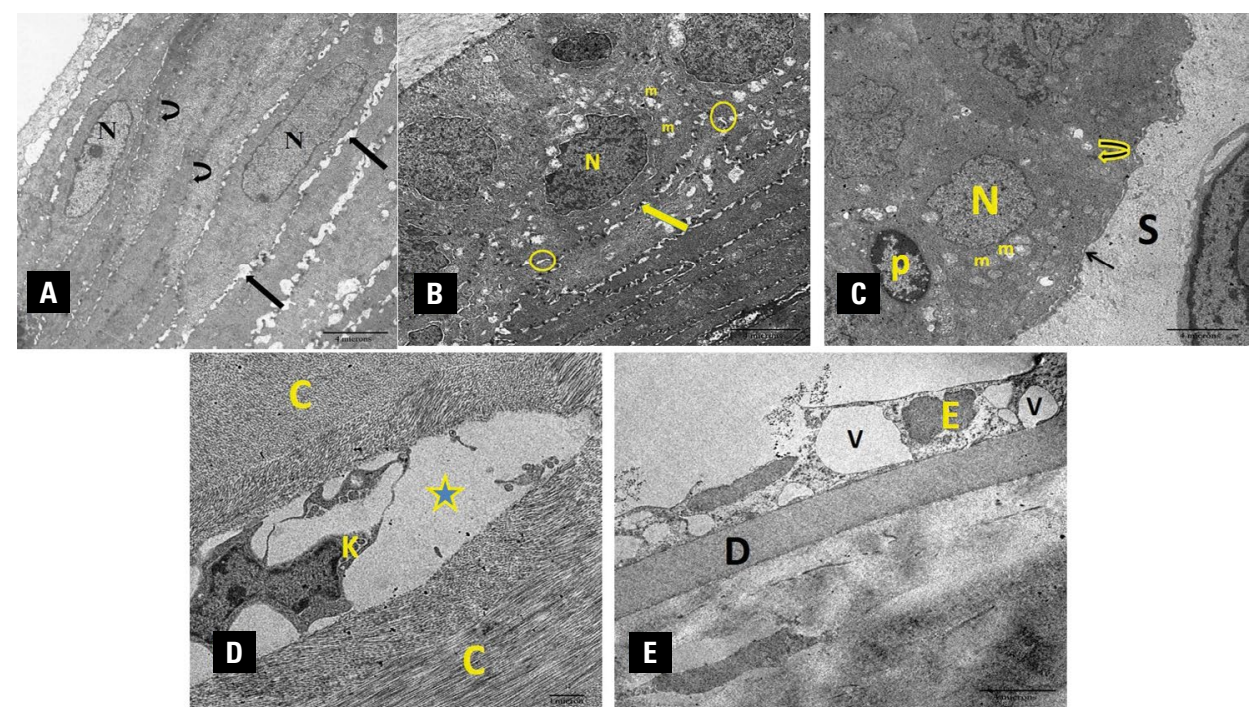

Figure 12. Electron micrographs of the cornea of intravenous bone marrow mesenchymal stem cells (BM-MSCs)-treated group; A. Squamous cells of superficial epithelial layer has an elongated euchromatic nucleus (N). The cells are connected together with intact continuous desmosomes (curved arrows); however, some cells are still separated by medium sized intercellular spaces (arrows); B. Cells of intermediate layer with irregular nucleus $(\mathrm{N})$, mitochondria $(\mathrm{m})$ with partial lysis of their cristae, intact normal desmosomes can be observed (arrow), slightly widening in intercellular spaces (circle); C. Some basal layer cells have irregular euchromatic nucleus (N) with multiple mitochondria $(\mathrm{m})$ while others have pyknotic nucleus (p). The cells are observed resting on a slightly irregular basement membrane (arrow). Desmosomes (curved arrows) could be seen connecting the cells with each other. The stroma shows a regular arrangement of the collagen fibrils (S); D. The stroma reveals well-organized regular collagen fibrils (C). A keratocyte (K) is observed with an irregular shape, distorted nucleus and surrounded by a large space devoid of collagen fibrils (asterisk); $\mathbf{E}$. The Descemet's membrane (D) appears thick, regular and homogenous in contour. Endothelial cell (E) is distorted with many vacuolations in its cytoplasm (V). Transmission electron microscopy A-C, E: $\times 8000$; scale bar $=4 \mu \mathrm{m} ; \mathrm{D}: \times 17500$; scale bar $=1 \mu \mathrm{m}$.
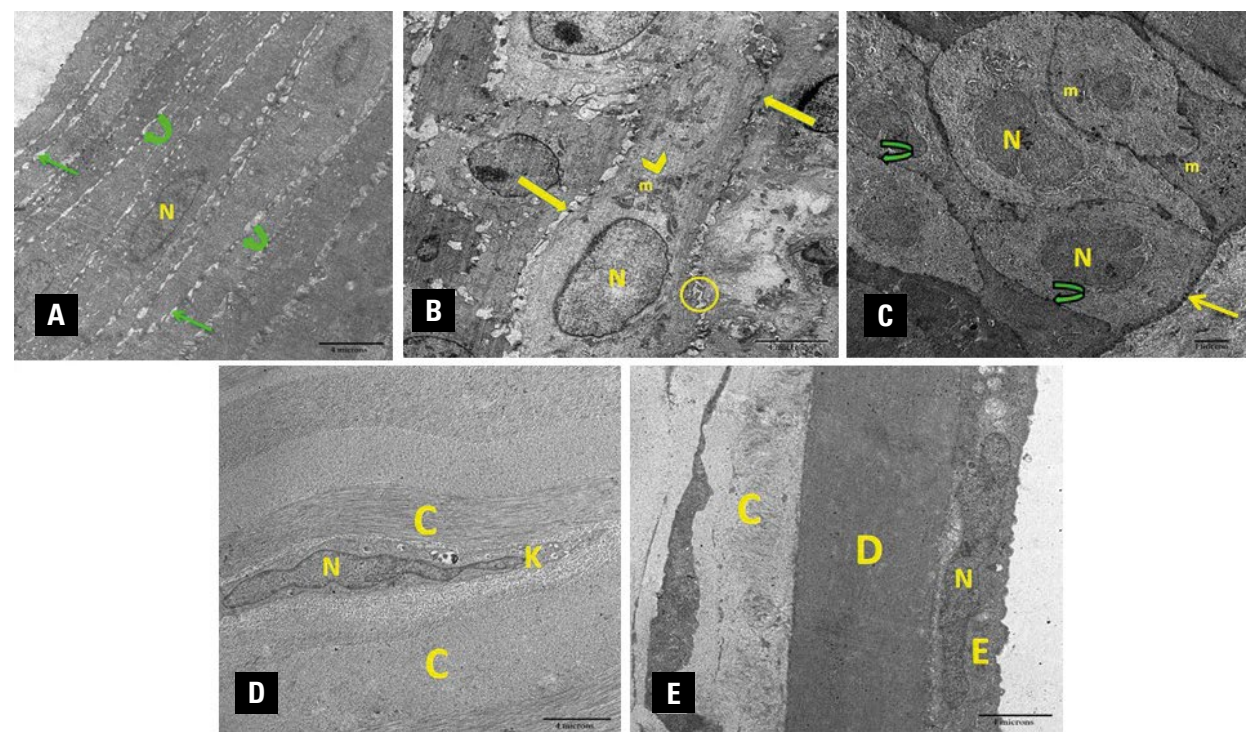

Figure 13. Electron micrographs of the cornea of subconjunctival bone marrow mesenchymal stem cells (BM-MSCs)-treated group (IV) showing marked improvement in all of its layers; A. Squamous cells in the superficial epithelial layer have a flattened elongated euchromatic nucleus (N). The cells are attached together by desmosomes (curved arrows). Narrow intercellular spaces are still seen among the cells (arrows); B. Cells of intermediate layer with nuclei appear nearly normal with regular outline (N). Mitochondria $(\mathrm{m})$ and rough endoplasmic reticulum (arrowhead) are normal. The junctional complex shows focal area of slightly widening in the intercellular space (circle) while the desmosomes are intact (arrow); C. The cells of basal layer possess a normal contour and an euchromatic mild indented nuclei (N) with many mitochondria $(\mathrm{m})$ resting on a regular intact continuous basement membrane (arrow). Intact desmosomes connecting the epithelial cells to each other (curved arrows); D. The stroma is seen with well-organized regular collagen fibrils (C). A spindle-shaped keratocyte (K) is observed with an euchromatic nucleus (N); E. Homogenous noncellular Descemet's membrane (D). The lining endothelial cell (E) has an elongated euchromatic nucleus $(\mathrm{N})$. Note: the regular organization of collagen fibrils in the stroma (C). Transmission electron microscopy A, B, D, E: $\times 8000$; scale bar $=4 \mu \mathrm{m} ; \mathrm{C}: \times 17500 ;$ scale bar $=1 \mu \mathrm{m}$. 
appeared homogenous and noncellular similar to the control one and its lining endothelial cells had an elongated euchromatic nucleus (Fig. 13E).

\section{Morphometric assessment}

The mean thickness of the corneal epithelium showed a highly significant decrease in the ultraviolet-irradiated group compared to the control one. Moreover, IV and SC injections in the BM-MSCs groups showed a non-significant decrease compared to the control group, On the contrary showed a significant increase compared to the ultraviolet-irradiated one (Table 1).

The mean colour intensity of PAS positive reaction and the mean thickness of the Descemet's membrane revealed a highly significant decrease in the ultraviolet-irradiated group compared to the control one. SC BM-MSCs group showed a highly significant increase compared to the ultraviolet-irradiated and IV BM-MSCs groups while a non-significant difference was recorded between SC BM-MSCs and control one (Table 2).

The mean area per cent of PCNA for all groups was represented in Table 3. There was a highly significant decrease in mean area per cent of PCNA immunoexpression in the ultraviolet-irradiated group compared to the control group. On the other hand, there was a significant increase in SC BM-MSCs group when compared to the other three groups.

\section{DISCUSSION}

The current study exhibited that BM-MSCs have a regenerative, anti-apoptotic and anti-inflammatory effects on the cornea exposed to ultraviolet radiation. This was assessed by histopathological, immunohistochemical and TEM evaluation. Local SC administration of BM-MSCs showed a better amelioration more than systemic IV administration on the corneal damage induced by UVB.

The cornea is avascular transparent structure, which permits the passage of light to the profound parts of the eyeball and is permanently at a high risk of exposure to a broad spectrum of radiation involving UV type [6]. Previous studies mentioned that the extent of injury resulted from UV radiation exposure is based on numerous factors, such as the time of exposure and the wavelength of radiation. Wavelengths under $290 \mathrm{~nm}$ are totally absorbed by the epithelial layer of the cornea then pass to the deep located structures, whereas those in the range between $300-320 \mathrm{~nm}$
Table 1. Corneal epithelial thickness of the study groups

\begin{tabular}{lc}
\hline Group & Corneal epithelial thickness \\
\hline Control group (group I) & $41.8 \pm 0.45$ \\
Ultraviolet-irradiated group (group II) & $24.6 \pm 0.54^{\mathrm{a}}$ \\
IV BM-MSCs group (group III) & $40.2 \pm 0.44^{\mathrm{b}}$ \\
SC BM-MSCs group (group IV) & $40.8 \pm 0.44^{\mathrm{b}}$ \\
\hline
\end{tabular}

Values are mean \pm standard deviation; ${ }^{a} p<0.05$ vs. group I and ${ }^{b} p<0.05$ vs. group II. Statistical analysis was performed by ANOVA, followed by Tukey's post-hoc test. BM-MSCs — bone marrow mesenchymal stem cells; IV — intravenous; SC — subconjunctival

Table 2. Thickness of Descemet's membrane and colour intensity of Periodic Acid Schiff (PAS)-positive reaction of the study groups

\begin{tabular}{lcc}
\hline Group & $\begin{array}{c}\text { Thickness of } \\
\text { Descemet's } \\
\text { membrane } \\
{[\mu \mathrm{m}]}\end{array}$ & $\begin{array}{c}\text { Colour } \\
\text { intensity of } \\
\text { PAS-positive } \\
\text { reaction }\end{array}$ \\
\hline Control group (group I) & $7.16 \pm 0.18$ & $21.36 \pm 0.60$ \\
Ultraviolet-irradiated group (group II) & $4.11 \pm 0.43^{\mathrm{a}}$ & $11.49 \pm 0.92^{\mathrm{a}}$ \\
IV BM-MSCs group (group III) & $5.94 \pm 0.46^{\mathrm{a}, \mathrm{b}}$ & $17.95 \pm 0.53^{\mathrm{a}, \mathrm{b}}$ \\
SC BM-MSCs group (group IV) & $7.07 \pm 0.34^{\mathrm{b}, \mathrm{c}}$ & $21.00 \pm 0.84^{\mathrm{b}, \mathrm{c}}$ \\
\hline
\end{tabular}

Values are mean \pm standard deviation; ${ }^{a} p<0.05$ vs. group I, ${ }^{b} p<0.05$ vs. group II and ${ }^{c} p<0.05$ vs. group III. Statistical analysis was performed by ANOVA, followed by Tukey's post-hoc test; BM-MSCs - bone marrow mesenchymal stem cells; IV — intravenous; SC — subconjunctival

Table 3. Proliferating cell nuclear antigen (PCNA) immunoexpression of the study groups

\begin{tabular}{lc}
\hline Group & PCNA immunoexpression \\
\hline Control group (group I) & $135.0 \pm 3.6$ \\
Ultraviolet-irradiated group (group II) & $113.8 \pm 3.1^{\mathrm{a}}$ \\
IV BM-MSCs group (group III) & $158.2 \pm 2.8^{\mathrm{a}, \mathrm{b}}$ \\
SC BM-MSCs group (group IV) & $176.0 \pm 2.6^{\mathrm{a}, \mathrm{b}, \mathrm{c}}$ \\
\hline
\end{tabular}

Values are mean \pm standard deviation; ${ }^{a} p<0.05$ vs. group I, b $p<0.05$ vs. group II and ${ }^{c} p<0.05$ vs. group III. Statistical analysis was performed by ANOVA, followed by Tukey's post-hoc test; BM-MSCs - bone marrow mesenchymal stem cells; IV — intravenous; SC — subconjunctival

are absorbed by the cornea and crystalline stroma, resulting in injury to several structures [50].

In this study, repeated application of UV radiation in the wavelength range between $290-400 \mathrm{~nm}$ for successive 5 days leads to epithelial desquamation of the cornea. Some epithelial cells revealed deeply stained nucleus and pale vacuolated cytoplasm. Furthermore, the thickness of corneal epithelium was markedly decreased in some focal areas. The stroma shower disturbed collagen fibres separated by wide spaces, neovascularisation and inflammatory infiltration. The Descemet's membrane seemed to be disorganized; some endothelial cells were disturbed with 
pale vacuolated cytoplasm. Current results were in accordance with Golu et al. [22], who concluded that repeated exposure to UV radiation with $290-400 \mathrm{~nm}$ wavelength resulted in necrosis of the membrane of the basal epithelium that may extend deeper to erode the Bowman's membrane. The Bowman's membrane was seen detached from the epithelium with fluid accumulation and damage of the junction in-between them. The Bowman's membrane was seen thickened, wavy and interrupted, permitting lymphocytes and macrophages migration in the anterior epithelium.

Similar findings have been reported by Chen et al. [12], who conducted a study on the mice which were subjected to UVB light $\left(0.72 \mathrm{~J} / \mathrm{cm}^{2} /\right.$ daily), and Mahmoud et al. [43], who applied a single UVB irradiation at a dose of $1.2 \mathrm{~J} / \mathrm{cm}^{2}$ on the cornea of the rats. The corneal epithelial thickness after UVB exposure appeared extremely thinner relative to the control group. The nuclei of the epithelial cells appeared more condensed, indicating cell death. UVB group showed considerable exfoliation of the corneal epithelium. Discontinuation or may be absence of the Bowman's membrane was clearly seen. Furthermore, the stroma revealed disarranged collagen fibres which were separated by wide spaces, keratocytes were degenerated and infiltrated by polymorphonuclear leukocytes, multiple lymphocytes, macrophages and haemorrhage $[22,43]$.

The current work revealed degenerated superficial epithelial cells with irregular basal cells, wide separation of corneal stroma and interruption of Descemet's membrane by electron microscopic examination. These findings were consistent with the ultrastructural study conducted by Mahmoud et al. [43] who showed irregular nuclear membrane, condensation of chromatin, absent rough endoplasmic reticulum and mitochondrial dissolution of the epithelial cells of the cornea.

Previous studies have reported many alterations of the corneal structure were induced by UV radiation by provocation of reactive oxygen species. Exposure of the cornea once to UVB radiation was enough to terminate endothelial cell proliferation. Marked decrease in the epithelial thickness was associated with higher doses of UVB [10]. Exposure to UV is associated with reduction of the oxygen removal rate from the cornea and blockage of glucose transmission system inside the cornea [34, 35]. Injury of the anterior corneal epithelium and endothelium is associated with UV exposure [48]. These results are matching with data of the present study which declare the presence of detachment in the layers of anterior epithelium and the endothelium after UV radiation exposure.

In the recent years, the cellular and molecular events inducing photokeratitis have been greatly investigated $[2,32]$. A variety of proinflammatory molecules including cytokines, nuclear factor-kappaB (NF-KB), interleukins and matrix metalloproteinases (MMPs) are involved in the disease progression [21, $37,49,59]$. NF-KB activation was generally reported to be provoked by UVB. The transcription of several down-stream genes such as inducible nitric oxide synthase (iNOS) and cyclooxygenase-2 (COX-2) is induced by NF- $\mathrm{KB}$. Both factors are the main activators of the induction of inflammatory cells $[12,23,27,39]$.

In the current work, the stroma was infiltrated by inflammatory cells. Wang et al. [60] reported that the damaged epithelial cells release interleukin 1 beta (IL1 $\beta$ ) which is responsible for inflammatory cellular reaction in the stroma. IL1 $\beta$ is an active cytokine that is implicated in immediate inflammatory reaction resulting in activation and infiltration by neutrophils and macrophages.

In the present study, neovascularisation of the corneal stroma was detected in the irradiated group. This was in accordance with Golu et al. [22] and Mureşan et al. [45] who reported the appearance of stromal neovascularisation of corneal stroma of the rat following prolonged ultraviolet exposure. Excess of pro-angiogenic agents, such as vascular endothelial growth factor (VEGF), MMPs and fibroblast growth factor (bFGF) and lack of antiangiogenic agents such as endostatin, angiostatin and pigment epithelium-derived factor resulted in imbalance between angiogenic and antiangiogenic factors which stimulate the avascular cornea to be vascularised [11]. VEGF were released from the basal layer epithelial cells, endothelial cells and fibroblasts of the cornea [49]. On the other hand, Clements and Dana [13] reported that the neovascularisation may occur due to inflammation.

In current study, BM-MSCs groups showed improvement in all parameters. These findings are in agreement with Harkin et al. [25] who emphasized that the healing of epithelium was improved by BMMSCs. There are different mechanisms by which the MSCs repaired the corneal damages such as growth factors and cytokines excretions that controlled cell proliferation and signalling after corneal alkali burn. Other study found that BM-MSCs-treated damaged 
corneas exhibited a marked amelioration and closure of the defects in the epithelium resulting in normal well-organized layers of epithelium with no intercellular gaps relative to the untreated corneas. Furthermore, the organized stromal structure is preserved by important factors such as keratan-sulfate proteoglycans which is released by the regenerated keratocytes. They are crucial and essentially needed for the transparency of the cornea by production and maintenance of normal collagen interfibrillar spacing and the fibril width [26].

The present results are in matching with Giacomini et al. [20] and Lazarus et al. [36] who demonstrated that BM-MSCs protected and accelerated healing of the corneal epithelium and endothelium resulting from free oxygen radicals and their oxidative stress via its immunomodulatory function through inhibition of leukocytes chemotaxis and phagocytosis of macrophages and suppression of release of free radicals. Previous researches conducted by Ma et al. [42] and Oh et al. [47] stated that promoted wound healing and ameliorated regeneration of the corneal surface were improved by MSCs therapy through its anti-inflammatory properties. Ma et al. [42] hypothesized that suppression of CD 45, interleukin 2 (IL-2) and MMP2 expression was produced due to the anti-inflammatory efficacy of MSCs. On the other hand, Oh et al. [47] reported that the anti-inflammatory properties of MSCs was achieved by blocking the adaptive CD4+ T cells invasion and also through suppression of CD4+ T cell-related cytokines and MMP2 expression potentially by releasing soluble agents.

In the current work, a highly significant decrease in PAS positive reaction in ultraviolet-treated group compared to the control was recorded, while statistically significant increase was recorded between MSCs-treated groups compared to ultraviolet-treated group. These findings are consistent with Sharaf Eldin et al. [52] who registered that after exposure to alkali burn, the Descemet's membrane of the cornea of the rat showed a mild positive reaction to PAS stain. On contrast, Ahmed et al. [1] recorded that after exposure to alkali burn the Descemet's membrane of the rabbit's cornea exhibited a significant increase in the thickness of the PAS positive reaction relative to control group. They concluded that the reduction in efficiency of the barrier in addition to a drop in the pump function resulting from variation in $\mathrm{pH}$ of the endothelium of the cornea is the main cause of the increase in the thickness of Descemet's membrane.
In this study, PCNA was highly expressed in basal epithelium and extended to the central and peripheral layers of the regenerated corneal epithelium in both IV and SC BM-MSCs-treated groups. In agreement with these finding, Ye et al. [62] mentioned that during the healing of corneal alkali burn, the efficacy of stem cell and the proliferation of cell kinetics were achieved by using stable cell cycle-regulated protein (PCNA). Expression of PCNA reaction is an indicator that MSCs promote the proliferation of limbal stem cells. This data suggested that the MSCs moved to the damaged cornea and induced native corneal cell proliferation. The probable interpretation of this suggestion is that many limbal stem cells were promoted by the transplanted MSCs in cornea; these stimulated stem cells react to the local specific medium produced by inflammatory reaction by secreting cytokines from MSCs, acquiring the ability to proliferate and differentiate. Thus, healing of the wound could be promoted by the transplanted MSCs through activating and synchronizing with native cells.

The corneas of IV BM-MSCs-treated group are still suffered from some residual histological alterations while SC BM-MSCs-treated group displayed corneas with nearly normal features. These findings are consistent with Shukla et al. [53] who assessed the effect of various routes of MSCs administration in amelioration of reconstruction and maintaining the transparency of cornea after inducing corneal damage in a murine model. They reported that SC and IV injections of MSCs after corneal damage are successful in dramatically reducing the inflammation and opacification in addition to repair and re-epithelialisation of the corneal tissue; however, there was slightly more improvement associated with the SC administration compared to IV route. The only interpretation is that SC route evades the MSCs aggregation of 'first-pass' in the lungs and decreases the possibility for residing outside the target and immunomodulatory impacts [54]. As the IV MSCs were retained in the lungs, huge numbers of cells are required to achieve the needed therapeutic effect, a consideration that decreases the possibility of using MSCs as a therapy in the clinical purposes $[5,31,64]$. On the other hand, administration of SC MSCs allowed the whole transplanted cells to reach the target with bypass of the first-pass action in the lung.

\section{CONCLUSIONS}

In summary, the current study exhibited that the local SC injection of BM-MSCs has a marvellous re- 
generative efficacy on the corneal tissue compared to the systemic IV injection of BM-MSCs. This occurs through inhibition of neovascularisation and suppression of the inflammatory reaction and degenerative changes of the epithelial cells induced by chronic ultraviolet irradiation exposure. Therefore, the usage of SC injection of BM-MSCs is recommended as a better therapeutic agent more than the IV injection in the chronic corneal injury.

\section{Conflict of interest: None declared}

\section{REFERENCES}

1. Ahmed SK, Soliman AA, Omar SMM, et al. Bone Marrow Mesenchymal Stem Cell Transplantation in a Rabbit Corneal Alkali Burn Model (A Histological and Immune Histo-chemical Study). Int J Stem Cells. 2015; 8(1): 69-78, doi: 10.15283/ijsc.2015.8.1.69, indexed in Pubmed: 26019756.

2. Alexander G, Carlsen H, Blomhoff R. Corneal NF-kappaB activity is necessary for the retention of transparency in the cornea of UV-B-exposed transgenic reporter mice. Exp Eye Res. 2006; 82(4): 700-709, doi: 10.1016/j. exer.2005.09.012, indexed in Pubmed: 16289165.

3. Ardan T, Němcová L, Bohuslavová B, et al. Reduced levels of tissue inhibitors of metalloproteinases in UVB-irradiated corneal epithelium. Photochem Photobiol. 2016; 92(5): 720-727, doi: 10.1111/php.12612, indexed in Pubmed: 27317620.

4. Bancroft JD, Gamble M. Theory and practice of histological techniques, 8th ed. Churchill Livingstone Elsevier, Philadelphia, London 2008: 333-354.

5. Barbash IM, Chouraqui P, Baron J, et al. Systemic delivery of bone marrow-derived mesenchymal stem cells to the infarcted myocardium: feasibility, cell migration, and body distribution. Circulation. 2003; 108(7): 863-868, doi: 10.1161/01. CIR.0000084828.50310.6A, indexed in Pubmed: 12900340.

6. Buddi R, Lin B, Atilano SR, et al. Evidence of oxidative stress in human corneal diseases. J Histochem Cytochem. 2002; 50(3): 341-351, doi: 10.1177/002215540205000306, indexed in Pubmed: 11850437.

7. Carvalho AM, Yamada A, Golim MA, et al. Characterization of mesenchymal stem cells derived from equine adipose tissue. Arq Bras Med Vet Zootec. 2013; 65(4): 939-945, doi: 10.1590/s0102-09352013000400001.

8. Cejka C, Kossl J, Hermankova B, et al. The healing of oxidative injuries with trehalose in uvb-irradiated rabbit corneas. Oxid Med Cell Longev. 2019; 2019: 1-10, doi: 10.1155/2019/1857086.

9. Cejka C, Luyckx J, Cejková J. Central corneal thickness considered an index of corneal hydration of the UVB irradiated rabbit cornea as influenced by UVB absorber. Physiol Res. 2012; 61(3): 299-306, doi: 10.33549/physiolres.932242, indexed in Pubmed: 22480421.

10. Cejková J, Stípek S, Crkovská J, et al. UV Rays, the prooxidant/antioxidant imbalance in the cornea and oxidative eye damage. Physiol Res. 2004; 53(1): 1-10, indexed in Pubmed: 14984308.
11. Chang JH, Garg NK, Lunde E, et al. Corneal neovascularization: an anti-VEGF therapy review. Surv Ophthalmol. 2012; 57(5): 415-429, doi: 10.1016/j.survophthal.2012.01.007, indexed in Pubmed: 22898649.

12. Chen BY, Lin DPC, Wu CY, et al. Dietary zerumbone prevents mouse cornea from UVB-induced photokeratitis through inhibition of NF- $\mathrm{KB}$, iNOS, and TNF- $\alpha$ expression and reduction of MDA accumulation. Mol Vis. 2011; 17: 854-863, indexed in Pubmed: 21527993.

13. Clements JL, Dana R. Inflammatory corneal neovascularization: etiopathogenesis. Semin Ophthalmol. 2011; 26(4-5): 235-245, doi: 10.3109/08820538.2011.588652, indexed in Pubmed: 21958169.

14. Diffey B. Sources and measurement of ultraviolet radiation. Methods. 2002; 28(1): 4-13, doi: 10.1016/s10462023(02)00204-9, indexed in Pubmed: 12231182.

15. Downes JE, Swann PG, Holmes RS. Differential corneal sensitivity to ultraviolet light among inbred strains of mice. Correlation of ultraviolet $B$ sensitivity with aldehyde dehydrogenase deficiency. Cornea. 1994; 13(1): 67-72, doi: 10.1097/00003226-199401000-00011, indexed in Pubmed: 8131409.

16. Eslani M, Putra I, Shen X, et al. Corneal mesenchymal stromal cells are directly antiangiogenic via PEDF and sFLT-1. Invest Ophthalmol Vis Sci. 2017; 58(12): 5507-5517, doi: 10.1167/iovs.17-22680, indexed in Pubmed: 29075761.

17. Filizay MC, Gokcinar NB, Sahinturk V, et al. Evaluation of retinol palmitate treatment of photokeratitis in rat eyes exposed to ultraviolet B radiation. Beyoglu Eye J. 2019; 4(2): 55-61, doi: 10.14744/bej.2019.51523, indexed in Pubmed: 35187434.

18. Gain P, Jullienne R, He Z, et al. Global survey of corneal transplantation and eye banking. JAMA Ophthalmol. 2016; 134(2): 167-173, doi: 10.1001/jamaophthalmol.2015.4776, indexed in Pubmed: 26633035.

19. Ghazaryan E, Zhang $Y$, He Y, et al. Mesenchymal stem cells in corneal neovascularization: Comparison of different application routes. Mol Med Rep. 2016; 14(4): 3104-3112, doi: $10.3892 / \mathrm{mmr} .2016 .5621$, indexed in Pubmed: 27514011.

20. Giacomini C, Ferrari G, Bignami F, et al. Alkali burn versus suture-induced corneal neovascularization in C57BL/6 mice: an overview of two common animal models of corneal neovascularization. Exp Eye Res. 2014; 121: 1-4, doi: 10.1016/j.exer.2014.02.005, indexed in Pubmed: 24560796.

21. Girolamo DN, Coroneo MT, Wakefield D. UVB-elicited induction of MMP-1 expression in human ocular surface epithelial cells is mediated through the ERK1/2 MAPK-dependent pathway. Invest Ophthalmol Vis Sci. 2003; 44(11): 4705-4714, doi: 10.1167/iovs.03-0356, indexed in Pubmed: 14578390.

22. Golu A, Gheorghişor I, Bălăşoiu AT, et al. The effect of ultraviolet radiation on the cornea - experimental study. Rom J Morphol Embryol. 2013; 54(4): 1115-1120, indexed in Pubmed: 24399010.

23. Golu T, Mogoantă L, Streba CT, et al. Pterygium: histological and immunohistochemical aspects. Rom J Morphol Embryol. 2011; 52(1): 153-158, indexed in Pubmed: 21424047. 
24. Hamill MB. Corneal trauma. In: Krachmer JH, Mannis MJ, Holland EJ eds. Cornea. 3rd (ed.). Mosby Elsevier, Saint Louis: 2010: 1176-1178.

25. Harkin DG, Foyn L, Bray $\sqcup$, et al. Concise reviews: can mesenchymal stromal cells differentiate into corneal cells? A systematic review of published data. Stem Cells. 2015; 33(3): 785-791, doi: 10.1002/stem.1895, indexed in Pubmed: 25400018.

26. Holan V, Trosan P, Cejka C, et al. A comparative study of the therapeutic potential of mesenchymal stem cells and limbal epithelial stem cells for ocular surface reconstruction. Stem Cells Transl Med. 2015; 4(9): 1052-1063, doi: 10.5966/sctm.2015-0039, indexed in Pubmed: 26185258.

27. Hur S, Lee YS, Yoo $\mathrm{H}$, et al. Homoisoflavanone inhibits UVB-induced skin inflammation through reduced cyclooxygenase-2 expression and NF-kappaB nuclear localization. J Dermatol Sci. 2010; 59(3): 163-169, doi: 10.1016/j.jdermsci.2010.07.001, indexed in Pubmed: 20724116.

28. Islam MM, Buznyk O, Reddy JC, et al. Biomaterials-enabled cornea regeneration in patients at high risk for rejection of donor tissue transplantation. NPJ Regen Med. 2018; 3: 2, doi: 10.1038/s41536-017-0038-8, indexed in Pubmed: 29423280

29. Jackson P, Blythe D. Immunohistochemical techniques (chapter 18). In: Suvarna SK, Layton C, Bancroft JD (eds.) Theory and practice of histological techniques. 7th ed. Churchill Livingstone of Elsevier, Philadelphia 2013: 381-426.

30. Kalleny N, Soliman N. Light and electron microscopic study on the effect of topically applied hyaluronic acid on experimentally induced corneal alkali burn in albino rats. Egypt J Histol. 2011; 34(4): 829-848, doi: 10.1097/01. ehx.0000407699.63226.2a.

31. Kean TJ, Lin P, Caplan Al, et al. MSCs: delivery routes and engraftment, cell-targeting strategies, and immune modulation. Stem Cells Int. 2013; 2013: 732742, doi: 10.1155/2013/732742, indexed in Pubmed: 24000286.

32. Kitaichi N, Shimizu T, Yoshida K, et al. Macrophage migration inhibitory factor ameliorates UV-induced photokeratitis in mice. Exp Eye Res. 2008; 86(6): 929-935, doi: 10.1016/j.exer.2008.03.009, indexed in Pubmed: 18436209

33. Kolozsvári L, Nogradi A, Hopp B, et al. UV absorbance of the human cornea in the 240 - to $400-\mathrm{nm}$ range. Investig Ophthalmol Vis Sci. 2002; 43(7): 2165-2168, indexed in Pubmed: 12091412

34. Lattimore MR. Effects of ultraviolet radiation on the oxygen uptake rate of the rabbit cornea. Optom Vis Sci. 1989; 66(2): 117-122, doi: 10.1097/00006324-19890200000010, indexed in Pubmed: 2710509.

35. Lattimore M. Glucose concentration profiles of normal and ultraviolet radiation-exposed rabbit corneas. Exp Eye Res. 1988; 47(5): 699-704, doi: 10.1016/00144835(88)90037-1.

36. Lazarus HM, Koc ON, Devine SM, et al. Cotransplantation of HLA-identical sibling culture-expanded mesenchymal stem cells and hematopoietic stem cells in hematologic malignancy patients. Biol Blood Marrow Transplant. 2005; 11(5): 389-398, doi: 10.1016/j.bbmt.2005.02.001, indexed in Pubmed: 15846293.
37. Lee DH, Kim JK, Joo CK. Translocation of nuclear factor-kappaB on corneal epithelial cells induced by ultraviolet B irradiation. Ophthalmic Res. 2005; 37(2): 83-88, doi: 10.1159/000084249, indexed in Pubmed: 15746563.

38. Li P, Zhang R, Sun $\mathrm{H}$, et al. PKH26 can transfer to host cells in vitro and vivo. Stem Cells Dev. 2013; 22(2): 340344, doi: 10.1089/scd.2012.0357, indexed in Pubmed: 22913652

39. Livezeanu C, Crăițoiu MM, Mănescu R, et al. Angiogenesis in the pathogenesis of pterygium. Rom J Morphol Embryol. 2011; 52(3): 837-844, indexed in Pubmed: 21892527.

40. Ljubimov AV, Saghizadeh M. Progress in corneal wound healing. Prog Retin Eye Res. 2015; 49: 17-45, doi: 10.1016/j.preteyeres.2015.07.002, indexed in Pubmed: 26197361.

41. Lohan P, Murphy N, Treacy O, et al. Third-party allogeneic mesenchymal stromal cells prevent rejection in a pre-sensitized high-risk model of corneal transplantation. Front Immunol. 2018; 9: 2666, doi: 10.3389/fimmu.2018.02666, indexed in Pubmed: 30515159.

42. Ma $Y, X u Y, X i a o ~ Z$, et al. Reconstruction of chemically burned rat corneal surface by bone marrow-derived human mesenchymal stem cells. Stem Cells. 2006; 24(2): 315-321, doi: 10.1634/stemcells.2005-0046, indexed in Pubmed: 16109757.

43. Mahmoud B, Shady A, Meleegy UEl, et al. Effects of ultraviolet $B$ radiation on the cornea of adult male albino rats and the possible role of lornoxicam: a histological, immunohistochemical and morphometrical study. Egypt J Histol. 2010; 33(1): 156-167, doi: 10.1097/00767537$201003000-00015$.

44. Mittal SK, Omoto M, Amouzegar A, et al. Restoration of corneal transparency by mesenchymal stem cells. Stem Cell Reports. 2016; 7(4): 583-590, doi: 10.1016/j.stemcr.2016.09.001, indexed in Pubmed: 27693426.

45. Mureşan S, Filip A, Mureşan A, et al. Histological findings in the Wistar rat cornea following UVB irradiation. Rom J Morphol Embryol. 2013; 54(2): 247-252, indexed in Pubmed: 23771066.

46. Nombela-Arrieta C, Ritz J, Silberstein LE. The elusive nature and function of mesenchymal stem cells. Nat Rev Mol Cell Biol. 2011; 12(2): 126-131, doi: 10.1038/nrm3049, indexed in Pubmed: 21253000.

47. Oh JY, Kim MK, Shin MiS, et al. The anti-inflammatory and anti-angiogenic role of mesenchymal stem cells in corneal wound healing following chemical injury. Stem Cells. 2008; 26(4): 1047-1055, doi: 10.1634/stemcells.2007-0737, indexed in Pubmed: 18192235.

48. Olsen EG, Ringvold A. Human cornea endothelium and ultraviolet radiation. Acta Ophthalmol (Copenh). 1982; 60(1): 54-56, doi: 10.1111/j.1755-3768.1982.tb05781.x, indexed in Pubmed: 7136528.

49. Pauloin $T$, Dutot $M$, Joly $F$, et al. High molecular weight hyaluronan decreases UVB-induced apoptosis and inflammation in human epithelial corneal cells. Mol Vision. 2009; 15: 577-583, indexed in Pubmed: 19325714.

50. Podskochy A. Protective role of corneal epithelium against ultraviolet radiation damage. Acta Ophthalmol Scand. 2004; 82(6): 714-717, doi: 10.1111/j.16000420.2004.00369.x, indexed in Pubmed: 15606469. 
51. Saghizadeh M, Kramerov AA, Svendsen CN, et al. Concise review: stem cells for corneal wound healing. Stem Cells. 2017; 35(10): 2105-2114, doi: 10.1002/stem.2667, indexed in Pubmed: 28748596.

52. Sharaf Eldin $\mathrm{H}$, Ibrahim M, Elswaidy N. A histological and immunohistochemical study of the effect of platelet- rich plasma on a corneal alkali burn in adult male albino rat. Egypt J Histol. 2019; 42(2): 482-495, doi: 10.21608/ ejh.2019.7018.1059.

53. Shukla S, Mittal SK, Foulsham W, et al. Therapeutic efficacy of different routes of mesenchymal stem cell administration in corneal injury. Ocul Surf. 2019; 17(4): 729-736, doi: 10.1016/j.jtos.2019.07.005, indexed in Pubmed: 31279065.

54. Sohni A, Verfaillie CM. Mesenchymal stem cells migration homing and tracking. Stem Cells Int. 2013; 2013: 130763, doi: 10.1155/2013/130763, indexed in Pubmed: 24194766.

55. Soleimani M, Nadri S. A protocol for isolation and culture of mesenchymal stem cells from mouse bone marrow. Nat Protoc. 2009; 4(1): 102-106, doi: 10.1038/ nprot.2008.221, indexed in Pubmed: 19131962.

56. Strober W. Trypan blue exclusion test of cell viability. Curr Protoc Immunol. 2001; Appendix 3: Appendix 3B, doi: 10.1002/0471142735.ima03bs21, indexed in Pubmed: 18432654.

57. Uccelli A, Moretta L, Pistoia V. Mesenchymal stem cells in health and disease. Nat Rev Immunol. 2008; 8(9): 726-736, doi: 10.1038/nri2395, indexed in Pubmed: 19172693.

58. Uccelli A, Moretta L, Pistoia V. Immunoregulatory function of mesenchymal stem cells. Eur J Immunol. 2006; 36(10):
2566-2573, doi: 10.1002/eji.200636416, indexed in Pubmed: 17013987.

59. Viiri J, Jauhonen HM, Kauppinen A, et al. Cis-urocanic acid suppresses UV-B-induced interleukin- 6 and -8 secretion and cytotoxicity in human corneal and conjunctival epithelial cells in vitro. Mol Vis. 2009; 15: 1799-1805, indexed in Pubmed: 19753313.

60. Wang Z, Handa JT, Green WR, et al. Advanced glycation end products and receptors in Fuchs' dystrophy corneas undergoing Descemet's stripping with endothelial keratoplasty. Ophthalmology. 2007; 114(8): 1453-1460, doi: 10.1016/j. ophtha.2006.10.049, indexed in Pubmed: 17320180.

61. Yao L, Li Zr, Su Wr, et al. Role of mesenchymal stem cells on cornea wound healing induced by acute alkali burn. PLoS One. 2012; 7(2): e30842, doi: 10.1371/journal. pone.0030842, indexed in Pubmed: 22363499.

62. Ye J, Yao K, Kim JC. Mesenchymal stem cell transplantation in a rabbit corneal alkali burn model: engraftment and involvement in wound healing. Eye (Lond). 2006; 20(4): 482-490, doi: 10.1038/sj.eye.6701913, indexed in Pubmed: 15895027.

63. Youn HY, McCanna DJ, Sivak JG, et al. In vitro ultraviolet-induced damage in human corneal, lens, and retinal pigment epithelial cells. Mol Vis. 2011; 17: 237-246, indexed in Pubmed: 21270970.

64. Zhang M, Mal N, Kiedrowski M, et al. SDF-1 expression by mesenchymal stem cells results in trophic support of cardiac myocytes after myocardial infarction. FASEB J. 2007; 21(12): 3197-3207, doi: 10.1096/fj.06-6558com, indexed in Pubmed: 17496162. 